\title{
CONTRIBUIÇÃO DA FENOMENOLOGIA HERMENÊUTICA PARA A PSICOLOGIA SOCIAL
}

\author{
Olga Sodré ${ }^{1}$ \\ Pontifícia Universidade Católica - RJ
}

\begin{abstract}
Esta apresentação da renovação atual da filosofia francesa ressalta as contribuições da fenomenologia hermenêutica de Ricoeur para a psicologia social ao enfocar a história pessoal e coletiva como um processo integrado à ação, à narração, à linguagem, à elaboração simbólica e à construção da identidade e alteridade. Sua abordagem histórica e cultural permite ultrapassar os limites do cartesianismo, positivismo e cognitivismo, aprofundando o estudo da subjetividade e de sua formação, inseridos na história pessoal, nas relações sociais, na experiência concreta e na história social mais ampla dos grupos, instituições e comunidades. Corresponde não apenas a um avanço no estudo da linguagem e da interpretação, como também ao surgimento de um novo paradigma da razão, o paradigma hermenêutico, e à criação de um método capaz de explorar novos aspectos da dinâmica psicossocial e de ser uma chave para a interpretação da pluralidade de linguagens e identidades na atual sociedade globalizada.

Descritores: Identidade. Alteridade. Representação. História. Narração.
\end{abstract}

\section{A renovação atual da Psicologia Social}

filosofia francesa está num momento de interessante renovação e a-
proximação com algumas das ciências humanas e sociais, em particu-

1 Psicóloga clínica com mestrado em Psicologia Clínica pela PUC/RJ, doutorado em filosofia pela Sorbonne / Paris IV e pós-doutorado em filosofia, no Institut Catholique de Paris, preparando, atualmente, um doutorado em psicologia na PUC-Rio de Janeiro. Endereço: Rua Barão de Ipanema, 139, Ap. 202. CEP 22050-030 - Rio de Janeiro, RJ. Endereço eletrônico: olgasodre@openlink.com.br 
lar com a sociologia e a história. Um exemplo bastante criativo a esse respeito é o da filosofia hermenêutica de Ricoeur (1969, 1980, 1987, 1990, 2000, 2003), que criou uma abordagem original para o estudo da questão da identidade e alteridade, com base na história de vida e na história social, no testemunho e na representação, na linguagem, na cultura e na narração. Esses assuntos interessam também à psicologia social, que atravessa um rico momento de reformulações teóricas, em particular, no Brasil. Assim sendo, procuro nesse artigo integrar as inovações no campo da filosofia hermenêutica e da psicologia social, refletindo sobre as possíveis articulações, contribuições e implicações dessa concepção filosófica para a pesquisa na área psicossocial.

Quando se estuda a psicologia social através de uma abordagem clássica, como a apresentada por Rodrigues, Assmar e Jablonski (2002), verifica-se a predominância da corrente cognitiva nessa área da psicologia, sendo ela definida por esses autores em termos dos processos cognitivos (p. 61). A Introdução à Psicologia Social de Krüger (1986), partindo dessa visão da psicologia social, analisa, contudo, criticamente suas principais características: o individualismo, o experimentalismo, a microteorização, o etnocentrismo, o utilitarismo, o cognitivismo e o a-historicismo. De fato, o cognitivismo, associado a uma metodologia experimental, enfrentou uma luta teórica com a psicanálise e o behaviorismo, tornando-se hegemônico no campo da psicologia social, na década de 40-50. Embora tendo enriquecido a psicologia social em muitos aspectos interessantes do processo de conhecimento, o cognitivismo enfatiza o controle racional das condutas humanas, preocupando-se com as construções e transformações lógicas, com a elaboração e com a articulação das estruturas cognitivas já formadas. Desse modo, negligencia ele a dimensão histórico-cultural e os aspectos não racionais do ser humano, que antes encontravam espaço nessa área da psicologia, como mostra a Introdução à Psicologia Social de Ramos (2003), publicada pela primeira vez em 1936, que retrata uma visão da psicologia social mais integrada às ciências sociais e mais interessada pelos aspectos dinâmicos da personalidade e dos grupos sociais. 
Uma série de livros brasileiros recentes sobre a psicologia social, como Psicologia Social Contemporânea, de Corrêa Jacques, Neves Strey, Guazzelli Bernardes, Guareschi, Carlos e Gali Fonseca (2002) mencionam uma crise dessa psicologia a partir de meados dos anos sessenta, que teria começado a chegar ao Brasil por volta dos anos setenta. Essa nova abordagem da psicologia social surge a partir das transformações do pensamento científico, nesse período, em particular, a partir das críticas aos fundamentos positivistas do chamado pensamento moderno. Criticam seus autores a perspectiva experimentalista e o pressuposto individualista que acabaram predominando na psicologia social de influência americana, após o período em que escreveu Ramos. Essa nova psicologia social enfatiza sua dimensão social, em particular, a partir de uma de suas mais influentes tendências, a da teoria das representações sociais, abrindo-se, igualmente, para a dimensão histórico-cultural do ser humano e da vida social.

Tentando romper com a dicotomia entre indivíduo e sociedade, as novas vertentes da psicologia social procuram se situar num espaço de interseção entre ambos, em particular, a partir de uma perspectiva psicológica de relação ao outro e de alteridade (Arruda, 1998). Essa psicologia social se constrói no Brasil, no final dos anos setenta e produz uma literatura sobre o assunto a partir dos anos oitenta, utilizando alguns referenciais da psicanálise, do materialismo histórico e de concepções sobre as representações sociais, as comunidades, as instituições e culturas. Os autores desses livros procuram romper com a linearidade de causas e efeitos e com a tentativa de controle experimental predominante na psicologia social americana, propondo um olhar sobre o concreto e sobre as relações sociais mais amplas e complexas.

Vários livros publicados, no Brasil, a partir da década de oitenta, fazem uma crítica à psicologia social anterior a essas transformações, propondo novos paradigmas para as ciências humanas. O livro organizado por Lane e Sawaia (1995), Novas Veredas da Psicologia Social e o organizado por Freitas Campos (2002), Psicologia Social Comunitária, ilustram bem o surgimento de uma nova vertente comunitária na psicologia social. Psicologia Social - Abordagens Sócio-Históricas e Desafios Contemporâneos, organi- 
zado por Jacó-Vilela (1999), representa outra nova vertente de cunho sóciohistórico, interdisciplinar e articulada com a antropologia, a história, a filosofia e a sociologia. Outros psicólogos e equipes de pesquisadores brasileiros atuais vêm contribuindo de forma inovadora para o estudo psicossocial da subjetividade, valorizando o processo histórico-social e o contexto cultural, entre eles os pesquisadores da pós-graduação em psicologia clínica da PUC-Rio. A psicologia social abre-se, desse modo, para campos novos de pesquisa, em particular o campo religioso, cujo estudo é apresentado por Paiva (1990), do Departamento de Psicologia Social e do Trabalho do Instituto de Psicologia da USP.

Ricoeur não menciona diretamente a psicologia social, mas existem psicólogos brasileiros trabalhando numa vertente social e fenomenológica, em relação com a história e a cultura, como Augras (1995, 2002). O fechamento da psicologia social no âmbito cognitivo e experimental levou alguns pesquisadores a se distanciarem dela, aproximando-se preferencialmente de outras ciências sociais, como a sociologia e a antropologia. Todavia, o campo de estudo da psicologia social tem tudo a ver com o enfoque da fenomenologia hermenêutica, que procuro aplicar às minhas pesquisas em psicologia social. A teoria da ação, por ele aprofundada, permite um distanciamento em relação à fenomenologia mais voltada para os fenômenos perceptivos e cognitivos, relacionando as representações com as práticas sociais. Esse movimento ocorreu, igualmente, no campo da psicologia social, como demonstra Jodelet (2001). O conceito de representação social se tornou, inclusive, o foco de estudo de uma importante escola de psicologia social: a da representação social, criada por Moscovici $(1984,1979)$.

A revisão crítica da psicologia social está, portanto, conduzindo a novas propostas e novos paradigmas, como se pode constatar pela leitura do livro Paradigmas em Psicologia Social, organizado por Freitas Campos e Guareschi (1996). Procura-se, nele, ultrapassar tanto o behaviorismo como o cognitivismo, abrindo a pesquisa dos processos de pensamento e aprendizagem para as relações e dinâmicas sociais e ligando as estruturas individuais às estruturas sociais. Denuncia-se a fragmentação das ciências humanas e sociais e da própria psicologia, ao separar a pesquisa acadêmica e a prática 
clínica. Aponta-se para a emergência de novos campos de pesquisa interdisciplinar, entre eles, o da pesquisa transcultural, indicando-se a influência de teóricos oriundos de campos diversos, trazendo temas novos como o processo civilizador, as transformações da intimidade, a confrontação dos agentes sociais em conflito, as transformações sociais e as ideologias dos grupos ou categorias sociais mais amplas. As investigações psicossociais são situadas em seu contexto, numa concepção dinâmica do psicossocial, que rompe as fronteiras entre a psicologia social e as demais ciências ou áreas da psicologia.

A contribuição dada pelas diferentes novas vertentes da psicologia social tem sido, portanto, muito rica, permitindo grandes avanços. Ocorreu, contudo, uma tendência a aprofundar os aspectos particulares do estudo da realidade psicossocial, colocando-se, em seguida, a necessidade de uma perspectiva mais abrangente e globalizadora, necessária para a articulação dos fenômenos psicossociais. Embora se reconheça a ampliação das temáticas e as propostas de mudança nos diferentes contextos sociais, considera-se importante ancorar tais propostas analíticas em projetos amplos, baseados em pressupostos filosóficos, que orientem a adoção dos instrumentos e a construção das categorias conceituais. De fato, é imprescindível avançar em toda essa reflexão, chegando à formulação de uma visão mais abrangente do psíquico em relação com sua dimensão histórica e cultural. Não se trata de abandonar o estudo cognitivo do processo de conhecimento e de sua produção social, nem de negar a importância das relações sociais em sua constituição, mas de evitar reduzir o psicológico ao cognitivo ou ao social, numa polarização das explicações exclusivamente em termos de um ou outro desses aspectos.

Tampouco me parece suficiente comple mentar o estudo parcial das representações sociais pelo estudo dos afetos, pois se mantêm as visões fracionadas do psicológico. Parece-me, sim, fundamental procurar complementar o estudo dos diferentes aspectos por uma visão mais global do psiquismo. Trata-se de abordar as diferentes formas de configuração psicológica e o processo de sua formação, inserido tanto na história pessoal, como nas relações sociais, na cultura e na história social mais ampla dos grupos, instituições e sociedades, como mostra Rey (2003), em Sujeito e Subjetividade, no 
qual integra as contribuições da psicologia social e da psicologia geral e clínica. A compreensão de Rey sobre o sujeito e a subjetividade aproxima-se do enfoque fenomenológico a respeito do papel ativo e participativo do sujeito concreto, inserido em sua condição atual, assim como da consciência como um processo orientado para a realidade e marcado por sua intencionalidade. Rey desenvolve uma visão integrada e global da psique e da experiência, inseridas nas relações sociais, na história social e na cultura. Embora adotando um enfoque marxista, sua abordagem psicossocial relacionada à fenomenologia apresenta pontos em comum com a fenomenologia hermenêutica.

A fenomenologia hermenêutica pode colaborar com as atuais tentativas da psicologia social de ampliar e aprofundar a sua área de estudos, ultrapassando os limites do cognitivismo e do positivismo. Como essa concepção se desenvolveu a partir de um processo semelhante de ruptura na área filosófica, o conhecimento do seu desenvolvimento é interessante para a psicologia social. $\mathrm{O}$ desenvolvimento da hermenêutica corresponde não apenas a um avanço no estudo da linguagem e da interpretação, como também ao aparecimento de um novo paradigma da razão, o paradigma hermenêutico. Além disso, esse novo método permite explorar aspectos novos da dinâmica psicossocial, podendo ser uma chave para a interpretação da pluralidade de linguagens e identidades na atual sociedade globalizada.

\section{O ser, o ato e o símbolo na idade hermenêutica da razão}

É, portanto, importante delinear o caminho que conduziu à sua descoberta, situando Ricoeur na perspectiva da história da filosofia. Em L'âge Herméneutique de la Raison, Greisch (1985) apresenta o surgimento da fenomenologia hermenêutica no contexto de uma mudança no enfoque da razão e do paradigma filosófico. Embora Greisch tenha usado essa expressão no contexto da história da filosofia, ela me parece ter implicações para as ciências humanas e sociais ao relacionar o predomínio de um tipo partic ular de racionalidade com um tipo de paradigma a ela associado. As mudan- 
ças no cenário da psicologia social acompanharam, igualmente, essas transformações no cenário intelectual, ocorridas na década de sessenta. Relaciono, portanto, as mudanças de paradigma na área das ciências humanas e sociais com essas idéias de Greisch. Tal abordagem tem a vantagem de não pretender uma caracterização mais ampla de determinado período da história social, assinalando apenas as mudanças no enfoque da razão.

Nos anos sessenta do século passado, surge uma nouvelle vague da fenomenologia francesa, que reformula os fundamentos estabelecidos pela fenomenologia alemã e renova a fenomenologia francesa, como mostra Greisch (2000) em outro livro, Le Cogito Herméneutique. Dando uma visão de conjunto desse movimento de renovação, delineia ele a passagem de uma fenomenologia de tipo descritiva para a fenomenologia hermenêutica. Enquanto a primeira focaliza mais o aspecto cognitivo da consciência, a segunda se volta para a interpretação dos sentidos da experiência vivida e se abre para o social. Esse movimento filosófico não apenas permitiu uma revisão crítica do racionalismo e do positivismo, como possibilitou repensar a relação entre ciência, filosofia e religião. A partir de 1965, Ricoeur lança as bases de uma fenomenologia hermenêutica, enxertando a prática hermenêutica de interpretação de textos no método fenomenológico e introduzindo novas perspectivas para o estudo da consciência, do ser e da linguagem.

Em Le Cogito Herm éneutique, Greisch (2000) ressalta a contribuição do movimento de renovação da fenomenologia hermenêutica francesa para a compreensão do ser ao nível da linguagem, da cultura e do mito. Indica, então, como esse movimento permite retomar questões fundamentais, tais como a da gênese do eu, da relação ao outro, do inconsciente, dos fenômenos de psicopatologia, das representações religiosas etc. A fenomenologia hermenêutica abre, portanto, uma perspectiva de enriquecimento não apenas da filosofia como também da própria psicologia. Greisch considera que a grande contribuição da atual fenomenologia hermenêutica francesa está na descoberta de que a compreensão do ser passa pelo símbolo e pela linguagem. Ricoeur articula a hermenêutica à teoria das significações de Husserl, ligando a ontologia à linguagem e ao conjunto dos atos, através dos quais a vida se manifesta. Ele critica a consciência pretensamente imediata como 


\section{Olga Sodré}

uma falsa consciência, concluindo ser necessário passar por uma exegese contínua das significações do mundo e da cultura para que a existência possa ter sentido e chegar à reflexão.

Greisch (2000) traça o quadro histórico da evolução da hermenêutica, inserindo a renovação da fenomenologia francesa numa longa cadeia de progressos sucessivos da filosofia, que não cabe aqui aprofundar, até atingir esse momento de renovação hermenêutica. Basta mencionar que, no século XIX, a reflexão se desloca dos aspectos técnicos da interpretação para os aspectos mais filosóficos da compreensão, provocando a emergência de uma hermenêutica filosófica. Friedrich Schleiermacher (1768-1834), considerado o pai da filosofia hermenêutica moderna, tenta dar um fundamento universal à análise do ato de compreender, ultrapassando o texto em direção às trocas verbais mais comuns. Só a partir do início do século XX, entretanto, desenvolve-se a filosofia hermenêutica propriamente dita, cujo desenvolvimento torna possível enfatizar a compreensão em relação à explicação, deixando, assim, de lado, a análise objetiva dos fatos e pondo em relevo a interpretação das significações. A compreensão passa a ser relacionada com o ser e não mais com o conhecer. Greisch (2000) sublinha que a publicação de Verdade e Método por Georg Gadamer, em 1960, na Alemanha, estabelece a filosofia hermenêutica em termos universais, em função de uma reflexão ampla sobre a linguagem e as ciências do espírito.

Na mesma época, Ricoeur desenvolve, na França, sua concepção original da hermenêutica, baseada num diálogo fecundo com as ciências da linguagem e do texto e com as ciências humanas e sociais, colocando o acento na questão do símbolo e integrando, num só campo do conhecimento, as contribuições da fenomenologia e da hermenêutica. A abordagem ontológica mais indireta de Ricoeur, pondo em evidência a mediação da linguagem e do texto, não reduz a questão do ser e da alteridade à dimensão meramente social da linguagem. A fenomenologia hermenêutica de Ricoeur permite uma nova visão da dinâmica da consciência, da linguagem e das significações intencionais, da relação do si-mesmo e da alteridade, levando em conta a perspectiva das comunidades históricas. 
Ricoeur se nutre, contudo, não apenas da contribuição fenomenológica para o estudo da experiência e da intencionalidade da consciência concreta e das descobertas da hermenêutica para a interpretação dos sinais e símbolos, mas também da abordagem de Nabert (1992, 1996a, 1996b) a respeito da reflexividade da consciência e do conhecimento de si-mesmo e do outro. A obra de ambos é extremamente importante para a psicologia em função de seu modo concreto de trabalhar a questão da consciência e do ser, numa forma totalmente oposta aos paradigmas que situam a consciência ou o sujeito ao nível universal. Nabert focaliza, por exemplo, a questão do mal radical partindo da consciência singular situada no mundo e enraizada nos sentimentos e julgamentos das questões da vida, das contradições que dilaceram o eu e das possibilidades de transformação da consciência movida pelo desejo.

O retorno ao caminho de pesquisa de si e de sabedoria, abandonado pela filosofia ocidental em seu encaminhamento especulativo, pode então ser retomado num outro nível de profundidade, pondo em evidência a divisão interna da consciência, separada de si-mesma. O método reflexivo de Nabert se aplica a uma consciência singular, buscando compreender-se em sua existência, enfrentando o desafio de estar separada de si e dilacerada por profundas contradições internas, mas tendo também a liberdade de buscar a unidade. Esse tipo de interrogação é impossível quando a reflexão gira em torno de um sujeito teórico situado ao nível das categorias universais. Nabert recusa todo enfoque que pressupõe a existência de consciências separadas, antes de entrarem em relação, mas também a existência de uma unidade ontológica preliminar, de um ser absoluto. Ele recusa a abstração do ser em geral, a objetivação de uma categoria universal de ser, preferindo referir-se à unidade do ato unificador da consciência e à possibilidade de compreensão de si, na busca da unidade consigo mesmo e com os outros.

Ele cria, assim, um método reflexivo de aprofundamento da consciência de si-mesmo no movimento para compreender-se. Essa busca das condições que assegurem o completo desabrochar da consciência de si, levam à constatação da impossibilidade de se atingir a igualdade consigo mesmo e à descoberta do outro da consciência diverso do si-mesmo. A análise reflexiva propõe, também, um retorno à fonte do símbolo e da interioridade no ato do 
pensamento, antes do despedaçamento desse ato através de seus meios de expressão. Procura-se, assim, ligar o sinal a seu ato fundador, como sublinha Ricoeur (2003), em "Jean Nabert: une Relecture". Esse movimento em direção à fonte do símbolo e do ato desperta o interesse pelo testemunho e pela compreensão das histórias de vida das pessoas, que passam a serem encaradas como textos a decifrar.

Ricoeur refere-se, então, à hermenêutica não apenas como decifração de textos escritos, mas também como decifração do grande texto da vida, das obras e instituições, situando sua visão hermenêutica no orbe da filosofia reflexiva de Nabert e dando continuidade ao seu trabalho "L'Acte et le Signe selon Jean Nabert", publicado em Conflit d'Interprétations. Essais d'Herméneutique (1969). Ricoeur sublinha, também, a contribuição de Nabert a respeito da fenomenologia do sentimento, numa abertura da consciência além dos limites do cognitivo:

Não seremos jamais suficientemente reconhecidos a Nabert por ter repatriado uma fenomenologia do sentimento na esfera reflexiva, como não mais se fez desde os Tratados das paixões da idade clássica. Pode-se dizer que o existencial em Nabert se reconquista sobre a estreiteza do cognitivo, na esteira de uma reflexão sobre o sentimento. (2003, p. 145)

Paralelamente a essa abertura para o sentimento, Ricoeur sublinha a ênfase dada por Nabert ao processo de realização humana pelas obras: “A obra dá corpo, espessura, visibilidade e legibilidade ao nosso desejo e nosso esforço. O que nós somos fundamentalmente se mostra no que nós fazemos. A obra (oeuvre) é realização (mise en oeuvre) do desejo" (2003, p. 146).* Ricoeur discerne a partir dessa relação entre o desejo e a obra, um cruzamento entre o fundamento de nosso desejo de ser e o histórico de sua inscrição num relato de vida, a nossa e a da comunidade à qual pertencemos. Ricoeur sublinha que a teoria do testemunho em Nabert surge, pela primeira vez, em relação com sua concepção de obra: "a obra aparecendo como o

2 O sinal *indica minha tradução do original para o português 
meio, o instrumento pelo qual uma 'afirmação criadora consegue testemunhar de si no mundo"' (2003, p. 147).*

Nabert torna assim possível romper com a concepção especulativa da consciência e do sujeito universais, ressituando a questão do Uno não mais fora do mundo e em relação a uma abstração transcendente, mas em relação ao ato e à consciência da unidade ou segundo uma vida em união com o outro. Esta é fundada na reciprocidade dos atos. A questão da compreensão de si pode, então, levar em conta a razão no encaminhamento do eu em busca de seu aperfeiçoamento. Para bem entender a originalidade do ato reflexivo em Nabert, é preciso não confundi-lo, contudo, com outras formas de reflexão, como bem mostrou Jean Greisch (2003), sublinhando a diferença entre o ato reflexivo para compreender-se e o conhecimento de si-mesmo como um objeto ou como a reflexão do eu no espelho da consciência. No ato reflexivo, observa-se uma presença a si-mesmo, que é uma retomada imediata e por inteiro de si, ao mesmo tempo subjetiva e objetiva, num despertar da consciência filosófica, oposto à de uma conquista de si, a um fechamento em si-mesmo ou a uma concepção subjetivista de interioridade.

Tendo recusado a redução da compreensão de si ao ato cognitivo do conhecimento de si, Nabert passa, então, da problemática do conhecimento à problemática do desejo, até ultrapassar toda subjetividade e chegar ao puro ato reflexivo de intimidade da consciência consigo mesma ou de presença irredutível a si mesma, que ultrapassa todas as formas nas quais se investe sua inquietude, até chegar à descoberta da identidade da consciência com o seu princípio, numa afirmação originária de si-mesmo enquanto ipseidade. Nabert não aceita, portanto, a idéia do ser que seria inicialmente fechado em si-mesmo, ou seja, a idéia do psiquismo como um sistema fechado ou de um eu tendo que aprender progressivamente a sair de si. Desde o início, o psiquismo é um campo aberto e, se o ser humano constrói defesas e procura se fechar, é justamente por não ser originalmente fechado. A relação ao outro (em particular aos pais) assim como a linguagem, na qual cada ser humano vem se inserir, existem antes mesmo da concepção. Assim sendo, a abertura vem antes e o fechamento dentro de si-mesmo vem depois. 


\section{Olga Sodré}

A fenomenologia e a filosofia reflexiva se referem à experiência, diferenciando-se, desse modo, da filosofia especulativa. O termo experiência, em filosofia, diz respeito a uma forma de conhecimento concreto adquirido pela observação, sendo distinto do emprego desse termo na área científica. No primeiro caso, trata-se da observação de um fenômeno, inclusive da própria consciência, no qual o observador é simples testemunha. Já seu emprego, associado ao método científico, tem o sentido da experimentação, que provoca fenômenos e manipula observações a fim de verificar as hipóteses de uma pesquisa. Villela-Petit apresenta de modo muito claro o emprego fenomenológico do termo experiência:

\footnotetext{
Retenhamos aqui a palavra experiência, que está longe de pertencer apenas às ciências empíricas ou experimentais. Ela é eminentemente fenomenológica. Sob o regime da redução transcendental, à qual nós fazíamos alusão, as análises fenomenológicas são, antes de tudo, análises da experiência. É a experiência, com efeito, que, em suas diferentes maneiras, é constitutiva de tudo que tem sentido e validade de ser para nós.” (2003, p. 21)*
}

Partindo da experiência de vida e da consciência concreta, a fenomenologia hermenêutica desenvolve uma concepção do ser em estreita relação com a linguagem, chegando assim a uma inovadora concepção do si-mesmo e do outro.

\section{Identidade, alteridade e narração}

Ricoeur tem sido um incansável pesquisador do si mesmo, cuja compreensão aprofundou de diferentes formas ao longo de toda sua obra, mas é em Soi-même Comme un Autre (1990) que ele sintetiza sua concepção do ser relacionada à concepção do outro e à hermenêutica, passando pela mediação dos sinais, dos símbolos e textos. Ao substituir o ego pelo si mesmo e recusar a centralidade do primeiro, ele atinge o próprio alicerce das filosofias que o colocam como fundamento e introduz a relação do si mesmo e do outro como o fundamento da consciência. Ricoeur mostra que, no movimento de reflexão da consciência, o ego aparece como um agente e um centro 
subtraindo-se ao mundo, enquanto que o si mesmo aparece como aberto à alteridade e por ela afetado. Ricoeur chega, então, à visão do cogito partido (cogito brisé), que leva em consideração as pesquisas sobre o inconsciente. Também sua abordagem do mito e dos símbolos não se situa apenas no nível racional, abrindo-se para uma compreensão mais ampla da consciência. Sua compreensão do si mesmo como outro rompe com a perspectiva individualista, sendo uma saída para a tendência de enfatizar o eu ou o outro.

Parece-me extremamente interessante a aproximação feita por Ricoeur entre a representação da ação, a narração e o si mesmo, assim como sua concepção da identidade narrativa e do personagem, desenvolvidas em Soimême Comme un Autre (1990). A descoberta dessa concepção do si-mesmo e de sua relação com a narração está ligada a um processo de ruptura com o racionalismo de tipo 〈objectivista». Ricoeur nunca recusou a razão, mas uma visão parcial e estreita da razão. Essa ruptura permite restabelecer a conexão entre a vida intelectual e os níveis mais profundos do ser, enraizados no impulso e na integração do universo imaginário e simbólico. A partir dessa ruptura, torna-se impossível aceitar a linearidade e simplificação do discurso racionalista, mas, sobretudo, a falta de conexão com a experiência e com a dinâmica da vida, que reduz a multiplicidade e pulsação do ser à linearidade de uma construção formal a-histórica, sem vida e dinamismo.

Ricoeur coloca o si-mesmo no lugar do "eu sou" ou do sujeito da linguagem. Ele rompe nesse nível com a filosofia do sujeito, enraizada na tradição do cogito e conjugada na primeira pessoa do singular. Considera ele como próprio das filosofias do sujeito e do cogito que elas sejam formuladas na primeira pessoa, e, portanto, como equivalentes as duas expressões: filosofias do sujeito e filosofias do Cogito. Ambas acabam sempre por colocar o eu seja em posição de força, seja de fraqueza. A antropologia filosófica de Ricoeur, baseada na hermenêutica do si-mesmo, distingue-se tanto da apologia do Cogito como de sua destituição. Enquanto, na tradição do Cogito, o sujeito encontra sua certeza nele mesmo e em seu pensamento, Ricoeur desloca o centro de gravidade para o si-mesmo em sua relação com o outro, colocando a história, a narração e a mudança no âmago do ser. 
Um aspecto fundamental da hermenêutica do si-mesmo na sua recusa da simplificação e unificação sob predomínio do Cogito passa pela mediação da linguagem e pela aceitação da multiplicidade de sentidos inerente à questão de quem fala e a respeito do que fala, de quem e sobre o que se faz um relato, assim como das diferentes maneiras de exprimir o discurso ao longo da história. A possibilidade de mudança, de variação de sentido e de aceitação da multiplicidade de expressões do ser diferencia a concepção de Ricoeur de outras concepções do si mesmo como um centro ou núcleo imutável. Ele se distancia de qualquer concepção do ser como essência ou substância fundamental, revalorizando a significação do ser como ato e potência, enraizada na pluralidade das significações do ser, da variação de sentidos e expressões históricas múltiplas. Distanciando-se da visão de transparência do sujeito em relação a si mesmo ou de qualquer tentativa de conhecimento direto e intuitivo de si mesmo, Ricoeur acentua a constituição indireta do simesmo pela mediação da linguagem, da ação e da narração, ligadas à capacidade reflexiva fundamental de designar-se como aquele que fala, que age (ou é capaz de ação intencional e de iniciativas que mudam o curso dos acontecimentos), que se narra, e a quem pode ser atribuída a responsabilidade e as conseqüências de seus atos. Para Ricoeur, o si-mesmo é, portanto, o autor, o narrador e o personagem de sua própria história, conferindo ele um papel central à mediação da narração na constituição do si-mesmo.

Ao mesmo tempo, sua visão do ser é intimamente relacionada à concepção da alteridade, instalada no próprio coração do ser. No cerne da consciência, a relação do si-mesmo ao Outro da consciência estabelece as bases da mudança constante do si-mesmo como outro. Tal perspectiva do ser imprime à sua ontologia a marca da diversidade de sentido, que afugenta a ambição de fundação última característica das filosofias do Cogito. Outra diferença entre a fenomenologia de Ricoeur e a filosofia do Cogito situa-se no modo de verificação proposto por ele com base na atestação ou no testemunho, que se opõe à certeza que reivindicam as filosofias do Cogito e se aproxima dos critérios de verificação dos saberes objetivos. Não se trata da simples crença, mas da crença com base no testemunho fiável, na crença com base na palavra da testemunha dos fatos relatados. Na base desses tes- 
temunhos está o processo de narração, que permite a Ricoeur chegar a uma concepção narrativa da identidade.

A narração tem um papel central na concepção do ser em Ricoeur. O si-mesmo não é para ele algo imutável, pronto e acabado, mas implica uma caminhada que conduz a pessoa ao si-mesmo, e na qual tem um papel fundamental a identidade narrativa. $\mathrm{O}$ acesso à compreensão de si-mesmo passa pela linguagem, pelo texto, pela elaboração dos sentidos de sua experiência e de suas relações, tendo, portanto, a narração sobre si-mesmo, uma importância central. O conhecimento de si é uma interpretação do texto da própria ação pela qual a pessoa acede a sua história. Ao aprofundar o seu estudo da Identidade Narrativa e da Ipseidade em Paul Ricoeur, considera VillelaPetit (1993) ${ }^{3}$ que, em Temps et Récit, Ricoeur (1987) busca estabelecer uma correlação entre a atividade de contar uma história e a temporalidade da experiência humana, vindo a elaborar a noção de identidade narrativa.

No final do terceiro volume de Temps et Récit, ele chega à conclusão de que há história, porque há nela quem age e quem sofre, isto é, um alguém (individual ou coletivo), que pode ser designado quando se pergunta quem teria feito ou agido de determinada maneira, ou seja, quando se indaga: A quem isso aconteceu? Para Ricoeur, em todo processo narrativo historiográfico ou de ficção literária há uma entidade individual ou coletiva podendo ser identificada através do próprio processo narrativo. Sublinha Villela-Petit que essa identidade narrativa não se torna conhecida senão através da própria história contada. A questão da identidade narrativa permite, então, a Ricoeur, pensar a identidade pessoal na dimensão temporal da existência humana de uma pessoa que se relaciona com as outras e se transforma no desenrolar de uma história.

É em função do poder da narração de transmitir o tempo, contando os fatos não em termos de descrição objetiva, mas em termos de um processo

3 Trata-se de um texto não publicado de uma Comunicação, apresentada no Colóquio Internacional Simone Weil $\left(50^{\circ}\right.$. Aniversário de morte) e Paul Ricoeur $\left(80^{\circ}\right.$. Aniversário de nascimento), realizado na UERJ, de 13 a 15 de setembro de 1993, cuja citação foi autorizada pela autora. 


\section{Olga Sodré}

de mudança, que integra o agente, a ação e o desenrolar dos fatos, que Ricoeur lhe confere um papel central em sua reflexão sobre a identidade pessoal. Não tendo reduzido a identidade pessoal a um substrato imutável, ele se propõe a fundamentar sua concepção da pessoa humana numa perspectiva histórica do ser no processo de mudança, abordando a identidade sob o ângulo da dimensão temporal e da relação ao outro. Ricoeur observa que na manutenção de si, através da palavra dada, ocorre uma forma de capacidade reflexiva, permitindo reconhecer-se como um agente idêntico ao longo do tempo. Esse processo ocorre na relação com um outro, pois a pessoa se comporta de tal forma que o outro possa contar com ela. Esse contar com torna-se, desse modo, a base da constituição do si-mesmo, de sua relação com o outro e da própria vida social.

A constituição do si-mesmo é, portanto, intimamente associada à relação ao outro e ao reconhecimento da alteridade. É no contexto da linguagem, da interlocução e da troca de pronomes pessoais, que ocorre o processo de constituição do si-mesmo e da alteridade. É a interpelação do outro que permite à pessoa tornar-se um si-mesmo e contrabalançar a tendência de fechamento do eu, numa dinâmica de reciprocidade a reversibilidade entre o si-mesmo e o outro. Ricoeur conclui que se não houvesse a capacidade de reflexividade e de iniciativa do si-mesmo, ele não poderia responder ao apelo do outro e deixaria de ter consistência. Admite ele haver uma anterioridade do outro, que nos desperta à responsabilidade. O outro nos interpela, solicita uma resposta e convida-nos ao diálogo. Todavia, a dialética do si-mesmo e do outro, assim como o diálogo, supõe a autonomia e reciprocidade dos dois pólos, que se manifesta, em particular, na troca dos pronomes pessoais entre duas pessoas, capazes de serem simultaneamente consideradas o eu e o outro. Ele vai mesmo mais adiante e observa que se o outro não pudesse ser também um si-mesmo, ele não poderia nem ser considerado um outro.

A ação e a linguagem contribuem para a constituição do si-mesmo, mas não são suficientes para explicar o processo de seu desenvolvimento e de suas mudanças. Para isso, é necessário considerá-lo não apenas como um sujeito que age e fala, mas também como o ator de uma história. $\mathrm{O}$ enfoque narrativo de sua história permite captar, ao mesmo tempo, a permanência e a 
mudança, que caracterizam a existência do si-mesmo. O percurso reflexivo, através do qual uma pessoa se torna um si-mesmo, integrando permanência e mudança, precisa ser expresso em uma narração capaz de apreender o desenrolar no tempo pela mediação da linguagem e do relato. A reflexão sobre o desenrolar do tempo e da história passa pelo acesso à narração, que desenha o traçado da experiência temporal. Para abordar a descrição do campo prático das ações e as narrações capazes de representar e estruturar a experiência temporal, Ricoeur toma emprestada de Aristóteles a noção de mimésis praxeôs, ou seja, de representação da ação.

O conhecimento dos personagens verídicos ou fictícios é feito através da narração de suas histórias. Tendo em vista a multiplicidade de suas ações e de suas falas, é preciso que o ator possa se reconhecer e ser reconhecido como a fonte única dessa multiplicidade ou como o agente único das múltiplas interlocuções e interações. Percebendo que a narração permite unificar a experiência temporal de cada um, Ricoeur estabelece uma íntima articulação entre experiência de vida, história, narração e ipseidade. Essa articulação se dá em torno da narração, mas se abre para o social, pois a concepção de um ser, seu nascimento e morte não podem ser contados senão pelos outros. A construção teórica de Ricoeur, apresentada em Soi-même Comme un Autre (1990), contém, desse modo, uma perspectiva social implícita, embora se situe, fundamentalmente, no campo de uma fenomenologia da consciência.

Em uma obra mais recente, La Mémoire, l'Histoire et l'Aubli (2000), ele faz, contudo, uma abertura ainda mais clara e direta para o social (e para as ciências humanas e sociais) ao tratar da questão da memória como memória coletiva e da história enquanto ciência social. Discutindo a questão de saber se a memória é primordialmente pessoal ou coletiva, sublinha o fato dessa questão só ter sido colocada tardiamente na história do conhecimento, em função do duplo movimento que fez emergir, de um lado, a problemática da subjetividade de contorno francamente egológico e, de outro lado, a sociologia com o conceito inédito de memória coletiva. Os Antigos (como Platão e Aristóteles) não se colocavam a questão de saber quem se lembra, mas se perguntavam o que significa ter ou buscar uma lembrança, preocupando-se apenas com a questão prática da relação entre o indivíduo e a cidade. 


\section{Passagem do pessoal ao social e representação histórica}

Ricoeur (1990) se preocupa com a integração do subjetivo e do objetivo, do pessoal e do social, opondo-se à eliminação da questão a respeito de quem realiza a ação, feita nas descrições impessoais, que se interessam pelas experiências sem se perguntar se elas provêm de pessoas ou vidas diferentes. Ele aceita as críticas feitas à egologia, à idéia de possessão e defesa dos próprios interesses, mas insiste sobre a importância de diferenciá-la da perspectiva da ipseidade, por ele defendida. Pondera que se a identidade própria perdesse toda a importância, a identidade do outro deixaria também de ter importância. A ênfase na dimensão impessoal dos acontecimentos anula a experiência pessoal e a condição corporal do ser, defendida por sua visão fenomenológica e pela hermenêutica da existência.

Sublinha Ricoeur a ligação da visão impessoal com o sonho tecnológico, que reduz a pessoa ao cérebro, anulando a possibilidade de imputabilidade das ações, a importância da ética e da relação ao outro, assim como a dimensão da vida e da história humana. Sem recusar o valor da descrição impessoal, defende a possibilidade de uma perspectiva pessoal e a própria noção de pessoa, assim como as questões relativas ao quem, ao ator e agente da história. Em sua visão histórica e narrativa, o acontecimento perde a sua neutralidade impessoal. Avaliando as contribuições de Ricoeur para a filosofia hermenêutica, Greisch (2001) põe em relevo sua compreensão narrativa do ser em relação com a gênese de uma hermenêutica da consciência histórica, a partir da análise da intriga narrativa no relato de ficção e no relato histórico. A condição histórica tem um sentido para os vivos, não estando limitada à história dos mortos. Esse sentido é existencial, narrativo e elaborado a partir dos acontecimentos, ações e paixões humanas.

Em La Mémoire, l'Histoire et l'Oubli, Ricoeur mostra bem a relação do surgimento de uma oposição do pessoal e do coletivo com o nascimento e diferenciação no campo das ciências humanas e sociais, assim como com a adoção de um modelo epistemológico baseado na objetividade da natureza. A fenomenologia nascente teria, então, sido levada a enfrentar a desconfian- 
ça de uma acusação infamante de psicologismo. Recusando ela própria tal rótulo, procura evitar, ao mesmo tempo, a tendência crescente à objetivação total da realidade humana. A oposição entre a tendência antiga de reflexividade e a tendência mais recente de objetividade não apenas teria se desenvolvido em termos de rivalidade, mas teria levado cada uma das tendências a se fecharem dentro de discursos, que acabam se tornando estranhos uns aos outros.

Ricoeur preocupa-se, então, em discernir as razões desse malentendido radical pelo exame de cada um desses discursos, na esperança de dar credibilidade à hipótese de uma constituição distinta, embora mútua e cruzada, da memória individual e coletiva. Partindo da concepção já desenvolvida anteriormente (1990) a respeito da capacidade de imputação, responsabilidade e atribuição a si-mesmo dos próprios atos, Ricoeur restitui ao ator a capacidade de apropriação dos seus atos, examinando algumas modalidades de troca entre a atribuição a si-mesmo dos fenômenos de memória e sua atribuição aos outros, estrangeiros ou próximos. Ricoeur distingue, então, a afirmação da importância do social e do coletivo, que ele reconhece, da tentativa de eliminação de todo e qualquer processo pessoal de atribuição a si-mesmo da iniciativa da ação. Ele critica a objetivação completa da memória, o que acaba por torná-la um mero reflexo do mundo material. Considera, ao contrário, que a memória implica uma ação prática de declarar que se viu e se fez algo, inserindo-se num processo de exploração prática do mundo, com iniciativas mentais e corporais que nos tornam sujeitos em ação, dotados de iniciativa e de capacidade de exercício da memória e de outras atividades psíquicas.

A partir dessa perspectiva de atribuição, Ricoeur tenta uma aproximação entre a tese fenomenológica e a tese sociológica sobre a memória. Procurando se diferenciar de uma fenomenologia de tipo idealista, ele se volta para uma fenomenologia aplicada à realidade social, no seio da qual participam sujeitos capazes de se designar, em graus diferentes de consciência refletida, como os autores de seus próprios atos. $\mathrm{O}$ movimento de abertura de Ricoeur para o social se baseia, em particular, no fato de as lembranças serem elaboradas numa linguagem comum, que é a linguagem dos outros. 
Não só o relato tem uma estrutura pública patente; também o testemunho é pronunciado, recebido e transmitido para outros, sendo eventualmente transformado em arquivo. Assim sendo, a experiência de outrem é considerada tão primordial como a experiência de si-mesmo. Nessa linha de reflexão social, Ricoeur chama a atenção para a dimensão plural de certas faculdades psíquicas em sua intrínseca referência ao outro ou em relação com a presença de outrem.

Essa extensão da fenomenologia à esfera social a aproxima da sociologia, que, em algumas orientações contemporâneas, faz igualmente um movimento de aproximação em direção à fenomenologia. Embora mais preocupado nesse livro com a historiografia, Ricoeur (2000) aponta alguns dados a respeito da sociologia. Em primeiro lugar, essa aproximação ocorrerá no campo da teoria da ação, exemplificada pela coletânea dirigida por Bernard Lepetit, que trata as formas de experiência do ponto de vista.da história social. A teoria da ação permite um distanciamento em relação à fenomenologia mais voltada para os fenômenos perceptivos e cognitivos, relacionando as representações com as práticas sociais. Ricoeur sublinha a existência de um plano intermediário entre o pólo da memória individual e o pólo da memória coletiva, onde ocorrem concretamente as trocas entre a memória viva das pessoas e a memória das comunidades às quais elas pertencem, que é particularmente estudado pela psicologia social.

Não caberia, no presente estudo, um aprofundamento da reflexão extremamente interessante feita por Ricoeur, em La mémoire, l'histoire et l'oubli (2000), a respeito da condição histórica e da historicidade do ser humano, mas não é possível deixar de salientar sua perspectiva sobre o caráter histórico e o aspecto temporal da existência humana. Ressaltando o fato de que o ser humano é não apenas capaz de lembrar-se como também de fazer história, Ricoeur relaciona essa capacidade com a análise da atestação e responsabilidade da ação humana e com a fenomenologia do testemunho e da representação da ação. O testemunho dá uma seqüência narrativa à memória, podendo ser recolhido, escrito, conservado, transformado em documentação, arquivado e consultado por outras pessoas. Assim se estabelece a relação íntima entre o testemunho, colocado na soleira da operação 
historiográfica, e a representação, que se constrói ao longo de toda essa operação até atingir o nível da explicação / compreensão.

A noção de representação atravessa todo o livro de Ricoeur (2000), desde a retrospectiva sobre a problemática grega do eikôn, a imagem mnemônica que torna presente o objeto ausente na mente, até chegar à operação historiográfica, considerada ela própria sob a forma da representação escrit urária do passado. A representação é considerada como um referencial privilegiado ao lado do econômico, do social e do político, sendo colocada no campo mais amplo da mudança social estudada pelo discurso histórico. Por se tratar, também, de um referencial central para a psicologia social, o estudo, feito por Ricoeur, sobre a noção de representação é precioso para os pesquisadores dessa disciplina. Não sendo possível reproduzir todo esse estudo neste artigo, sublinho apenas que ele parte de uma revisão histórica da utilização do termo mentalidade (criticando, em particular, o termo de mentalidade primitiva), até chegar à substituição desse termo pela noção de representação, no terceiro terço do século XX, quando ela é, igualmente, introduzida na psicologia social.

Refletindo sobre essa mudança na linguagem científica, Ricoeur conclui: "Em oposição, portanto, à idéia unilateral, indiferenciada e massiva de mentalidade, a idéia de representação exprime melhor a pluralidade de vozes, a diferenciação, a temporalização múltipla dos fenômenos sociais" (2000, p. 292).* As representações são, então, apresentadas como componentes simbólicos na estruturação dos laços sociais e identidades, em estreita relação com as experiências, as práticas, narrações e discursos históricos dos agentes sociais. O próprio historiador, ao levantar ou consultar os testemunhos, vem com suas questões e representações próprias e elabora novas representações. Ricoeur alerta, portanto, para a ilusão que confunde o fato histórico com o que realmente aconteceu e a tentação de confundir a narração histórica com a simples ficção. O fato histórico é construído a partir dos testemunhos e documentos, num longo trabalho de operação historiográfica, que permite sua refutação e verificação. 


\section{Olga Sodré}

Nesse esforço de reflexão, Ricoeur se serve de obras consagradas ao estudo da psicologia histórica, especialmene, a de Robert Mandrou e a de Pierre Vernant, assim como dos trabalhos da nova história (inserida no grupo reunido em torno da revista Annales) e da contribuição de Norbert Elias para a história das mentalidades e das representações. Essa íntima relação com a história transparece na expressão, por ele adotada, representação histórica. Ao falar de representação histórica, Ricoeur enfatiza o processo, a ação, os autores e atores das representações, assim como a dinâmica entre permanência e mudança, integrando esse conceito a uma ampla concepção do ser humano e ao enfoque da fenomenologia hermenêutica, por ele criado. Esse enfoque da representação, assim ampliado e enraizado na fundamentação histórico-social da fenomenologia, parece-me trazer um grande enriquecimento para a psicologia social.

Recusando a idéia de uma oposição entre ação e representação, Ricoeur procura situar a ação no seu papel de estruturação da experiência viva, em conjugação, e não em termos de oposição, com a representação: “A tendência geral da presente obra é a de tomar o par da ação e da representação pela matriz dupla do laço social e das identidades que instituem esse último" (2000, p. 568). Assim sendo, é o par formado pela ação e pela representação, que forma os laços e identidades sociais. Essa conclusão se insere perfeitamente numa visão do ser como potência e ato e não como substância, atributo e acidente, numa perspectiva fenomenológica que parte da experiência viva. Em consequiência disso, Ricoeur atribui um papel central a essa experiência viva no reconhecimento e manutenção das imagens através da associação entre ação e representação: "É nessa experiência viva que se atesta a sinergia entre ação e representação" (p. 569). *É a própria experiência viva que sobrevive, enquanto inscrição psíquica: "a inscrição, no sentido psíquico do termo, não é outra coisa senão a sobrevivência da imagem mnemônica contemporânea da experiência originária" (pp. 569-70).*

Ao enfocar a história, tanto no ní vel mais amplo e coletivo como no nível pessoal das identidades narrativas e das histórias de vida, como um processo integrado intimamente associado à ação, à narração, à linguagem e ao símbolo, Ricoeur lança as bases de uma abordagem histórico-cultural, 
que pode ser extremamente enriquecedora para a psicologia social. Sua metodologia distingue-se das tendências de descrição externa e objetiva dos fatos históricos, voltando-se para o testemunho do agir, da experiência e das descobertas humanas. Abre ele, assim, a história para uma dimensão subjetiva também estudada pela psicologia social. Nessa perspectiva aberta por Ricoeur, as subjetividades, as relações e ações humanas inserem-se num processo mais amplo de criação e transformação do mundo, de si-mesmo e da relação ao outro. Seu enfoque dinâmico e histórico da identidade narrativa das pessoas concretas se diferencia de uma visão a-histórica e meramente cognitiva do ser humano, indo ao encontro das críticas atuais levantadas a esse respeito pelos psicólogos sociais. Ricoeur oferece uma perspectiva histórico-cultural mais abrangente e integrada dos diferentes aspectos do psiquismo (identidade, alteridade, capacidade de ação e narração, representação, cognição, afetividade, relações sociais etc.), imprescindível para a articulação dos fenômenos psicossociais e para uma visão mais ampla dessa área da psicologia. Sua concepção permite um aprofundamento da subjetividade e do processo de sua formação, inseridas tanto na história pessoal, como nas relações sociais, na cultura, no processo de elaboração simbólica e de busca de sentido, assim como na experiência social concreta e na história social mais ampla dos grupos, instituições e sociedades.

Sodré, O. (2004). Hermeneutical Phenomenology contribution b Social Psychology. Psicologia USP, 15(3), 55-80.

\begin{abstract}
This presentation of the current French philosophy's renewal underlines Ricoeur's hermeneutical phenomenology contributions to social psychology, since it focuses the personal and collective history as a process integrated to action, narration, language, symbolical elaboration and the construction of identity and alterity (otherness). His historical and cultural approach makes it possible to go beyond the limits of cartesianism, positivis $m$ and cognitivism, deepening the study of the subjectivity and its formation, inserted in the personal history, in social relations, in concrete experience and in the broader social history of groups, institutions and communities. It corresponds not only to a progress in the study of language
\end{abstract}




\section{Olga Sodré}

and interpretation, but also to the rising of a new paradigm of Reason, the hermeneutical paradigm, and to the creation of a method capable of exploring new aspects of the psychosocial dynamics, besides being a key to the interpretation of the plurality of languages and identities of the present globalized society.

Index terms: Identity. Alterity. Hermeneutics. Phenomenology.

Sodré, O. (2004). Contribution de la phénoménologie herméneutique à la psychologie sociale Psicologia USP, 15(3), 55-80.

Résumé: Cette présentation de la rénovation actuelle de la philosophie française met en évidence les contributions de la phénoménologie herméneutique de Ricoeur à la psychologie sociale, par sa mise au point de $1^{\prime}$ histoire personnelle et collective comme un processus intégré à l'action, à la narration, au langage, à l'élaboration symbolique et à la construction de l'identité et de l'altérité. Son approche historique et culturelle permet de dépasser le cartésianisme, le positivisme et le cognitivisme, approfondissant l'étude de la subjectivité et de sa formation, intégrés à l’histoire personnelle, aux rapports sociaux, à l'expérience concrète et à l'histoire sociale plus large des groupes, institutions et communautés. Il correspond non seulement à un progrès dans l'étude du langage et de l'interprétation, mais aussi à $l^{\prime}$ émergence d'un nouveau paradigme de la raison, le paradigme herméneutique, ainsi qu'à la création d'une méthode capable d'explorer des nouveaux aspects de la dynamique psychosociale et d'être une clé pour l'interprétation de la pluralité de langages et d'identités dans la société globalisée actuelle.

Mots clés: Identité. Altérité. Herméneutique. Phénoménologie.

\section{Referências}

Arruda, A. (Org.) (1998). Representando a alteridade. Petrópolis, RJ: Vozes.

Assmar \& Jablonski (2002)

Augras, M. (1995). Alteridade e dominação no Brasil - psicologia e cultura. Rio de Janeiro: NAU. 
Augras, M. (2002). O ser da compreensão (10a ed.). Petrópolis, RJ: Vozes.

Corrêa Jacques, M. G., Neves Strey, M., Guazzelli Bernardes, N. M., Guareschi, P. A., Carlos, S. A., \& Gali Fonseca, T. M. (2002). Psicologia social contemporânea (6a ed.). Petrópolis, RJ: Vozes.

Freitas Campos, R. H. de, Guareschi, P. (Orgs.). (1996). Paradigmas em psicologia social (2a ed.). Petrópolis, RJ: Vozes.

Freitas Campos, R. H. de (Org.). (2002). Psicologia social comunitária (8a ed.). Petrópolis, RJ: Vozes.

Greisch, J. (1985). L'âge herméneutique de la raison. Paris: Cerf.

Greisch, J. (2000). Le cogito herméneutique. Paris: Vrin.

Greisch, J. (2001). Paul Ricoeur. L' ltinérance du sens. Grenoble, France: Jérôme Millon.

Jacó - Vilela, A. M. (Org.). (1999). Psicologia social-abordagens sócio - históricas e desafios contemporâneos. Rio de Janeiro: UERJ.

Jodelet, D. (Org.). (2001). As Representações sociais. Rio de Janeiro: EdUERJ.

Lane, S., \& Sawaia, B. (Orgs.). (1995). Novas veredas da psicologia social. São Paulo: Brasiliense; EDUC.

Krüger, H. (1986). Introdução à psicologia social. Rio de Janeiro: E.P.U.

Moscovici, S. (1984). Psychologie sociale. Paris : PUF.

Paiva, G. J. de (1990). Algumas relações entre Psicologia e Religião. Psicologia USP, 1(1), 25-33.

Nabert, J. (1992). Éléments pour une éthique. Paris: Aubier.

Nabert, J. (1996a). Essai sur le mal. Paris: Cerf.

Nabert, J. (1996b). Le désir de Dieu. Paris: Cerf.

Ramos, A. (2003). Introdução à psicologia social (4a ed.). São Paulo: Casa do Psicólogo.

Ricoeur, P. (1969). Conflit d'interprétations. Essais d'herméneutique. Paris: Seuil.

Ricoeur, P. (1980). Philosophie de la volonté I. Paris: Aubier.

Ricoeur, P. (1987). Temps et récit. Paris: Seuil.

Ricoeur, P. (1990). Soi-même comme un autre. Paris: Seuil.

Ricoeur, P. (2000). La mémoire, l'histoire l'oubli. Paris: Seuil. 


\section{Olga Sodré}

Ricœur, P. (2003). Jean Nabert: une relecture. In P. Capelle (Ed.), Jean Nabert et la question du divin. Paris: Cerf.

Rey, F. G. (2003). Sujeito e subjetividade. São Paulo: Pioneira Thomson Learning.

Rodrigues, A., Assmar, E. M. L., \& Jablonski, B. (2002). Psicologia social (21a ed.). Petrópolis, RJ: Vozes.

Villela-Petit, M. (1993). Identidade narrativa e ipseidade em Paul Ricoeur. Rio de Janeiro: UERG. (Trabalho não publicado)

Villela-Petit, M. (2003). Comment la conscience de soi s’assure-t-elle de lídée du divin? In P.Capelle (Ed.), Jean Nabert et la question du divin . Paris: Cerf.

Recebido em 1.03.2004

Aceito em 10.05.2004 